\title{
INFLUÊ NCIA DO CÁLCIO SOBRE O CRESCIMENTO E SOLUTOS EM PLÂNTULAS DE SORGO ESTRESSADAS COM CLORETO DE SÓDIO(1)
}

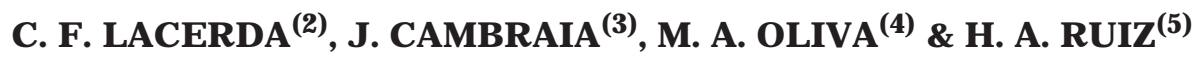

\begin{abstract}
RESUMO
O aumento da concentração de Ca no ambiente radicular tem sido indicado para reduzir os efeitos deletérios da salinidade sobre o cresci mento das plantas. Neste trabal ho, plântulas de dois genóti pos de sorgo for rageiro [Sorghum bicol or (L.) Moench], um tolerante (CSF 20) e outro sensível (CSF 18) à salinidade, foram expostas a duas concentrações de $\mathrm{Na}^{+}\left(0\right.$ e $\left.75 \mathrm{mmol} \mathrm{L}^{-1}\right)$ e duas de $\mathrm{Ca}^{2+}(0,65$ e 2,6 mmol L-1), em solução nutritiva, em arranjo fatorial $2 \times 2 \times 2$. Após sete dias de tratamento, foram determinados a produção de matéria seca e os teores de $\mathrm{Cl}^{-}, \mathrm{Na}^{+}, \mathrm{K}^{+}, \mathrm{Ca}^{2+}$ e de prolina em folhas e raízes. $\mathrm{O}$ estresse salino reduziu a produção de matéria seca nas duas partes das plântulas dos dois genótipos, principalmente do sensível, enquanto o aumento na concentração de $\mathrm{Ca}^{2+}$ no meio de cultivo amenizou parcialmente este efeito, princi palmente na parte aérea do genótipo tolerante. O estresse salino também acarretou aumento nos teores de $\mathrm{Na}^{+}$e de $\mathrm{Cl}^{-}$e redução nos teores de $\mathrm{K}^{+}$nas duas partes das plântulas dos dois genóti pos, especialmente do sensível. Adicionalmente, observou-se redução nos teores de $\mathrm{Ca}^{2+}$, bem como aumento nos teores de prolina, mas apenas nas folhas. 0 aumento na concentração de $\mathrm{Ca}^{2+}$ amenizou estes efeitos, reduzindo os teores de $\mathrm{Na}^{+}$e Cl-e aumentando os teores de $\mathrm{K}^{+}$, principalmente nas folhas do genóti po tolerante. Este genóti po apresentou uma relação $\mathrm{Na}^{+} / \mathrm{K}^{+}$bem inferior à observada no genótipo sensível, diferença esta que se acentuou ainda mais com o aumento da concentração de $\mathrm{Ca}^{2+}$ na solução nutritiva. $\mathrm{O}$ aumento na concentração de $\mathrm{Ca}^{2+}$ no meio nutritivo resultou em aumento nos teores $\mathrm{de} \mathrm{Ca}^{2+}$ em folhas e raízes dos dois genótipos, porém as plântulas estressadas não foram capazes de manter as mesmas concentrações desse íon observadas nas plântulas-controle. $\mathbf{O} \mathrm{Ca}^{2+}$ não teve qualquer efeito significativo sobre o acúmulo de prolina nas plântulas, submetidas ou não a estresse salino.
\end{abstract}

Termos de indexação: salinidade, Sorghum bicolor, crescimento, $\mathrm{Cl}^{-}, \mathrm{Na}^{+}$e $\mathrm{K}^{+}$.

\footnotetext{
(1) Parte da Tese de Doutorado do primeiro autor, submetida à Universidade Federal de Viçosa - UFV. Trabalho financiado pela FAPE MIG e CNPq. Recebido para publicação em dezembro de 2002 e aprovado em janeiro de 2004.

(2) Professor Adjunto do Departamento de Engenharia Agrícola, Universidade Federal do Ceará - UFC. CEP $60021-970$ Fortaleza (CE). E-mail: cfeitosa@ufc.br;

(3) Professor Titular do Departamento de Biologia Geral, Universidade Federal de Viçosa - UFV. CEP 36570-000 Viçosa (MG). Bolsista do CNPq. E-mail: cambraia@ufv.br

(4) Professor Titular do Departamento de Biologia Vegetal, UFV. Bolsista do CNPq. E-mail: molina@ufv.br

(5) Professor Titular do Departamento de Solos, UFV. Bolsista do CNPq. E-mail: hruiz@ufv.br
} 


\title{
SUMMARY: CALCIUM EFFECTS ON GROWTH AND SOLUTE CONTENTS OF SORGHUM SEEDLINGS UNDER NACL STRESS
}

\begin{abstract}
I ncreased $\mathrm{Ca}^{2+}$ concentrations in theroot envi ronment havebeen suggested to mi nimize salinity effects on plant growth. In this work, seedl ings of two forage sorghum genotypes (Sorghum bicolor (L.) Moench), onesalt tol erant (CSF 20) and theother salt sensitive (CSF 18), were exposed to two $\mathrm{Na}^{+}\left(0\right.$ and $\left.75 \mathrm{mmol}^{-1}\right)$ and two $\mathrm{Ca}^{2+}\left(0.65\right.$ and $\left.2.60 \mathrm{mmol}^{-1}\right)$ leve s in nutrient solution, in a $2 \times 2 \times 2$ factorial design. After seven days of salt treatment, the shoot and root dry matter as well as $\mathrm{Cl}^{-}, \mathrm{Na}^{+}, \mathrm{K}^{+}, \mathrm{Ca}^{2+}$, and proline concentration were measured. Salt stress reduced shoot and root dry matter yield in both genotypes, especially in the salt sensitive genotype. An increase in $\mathrm{Ca}^{2+}$ concentration in the nutrient solution partial ly reduced thesalt effects, mainly in theshoots of thesalt tolerant genotype. Thesalt stress al so increased leaf and root $\mathrm{Na}^{+}$and $\mathrm{Cl}^{-}$concentration but reduced that of $\mathrm{K}^{+}$in both genotypes, especially in thesensitiveone. Additionally, a reduction in $\mathrm{Ca}^{2+}$ and an increase in prolineconcentration were observed, though only in theleaves. Theincrease in the $\mathrm{Ca}^{2+}$ concentration in solution partially all eviated the salt effects by reducing $\mathrm{Na}^{+}$and $\mathrm{Cl}^{-}$and increasing $\mathrm{K}^{+}$contents, especially in the leaves of the salt tolerant genotype. This genotype presented a much lower $\mathrm{Na}^{+} / \mathrm{K}^{+}$ratio than the sensitive one, and this difference between genotypes increased along with the increasing $\mathrm{Ca}^{2+}$ concentration in the nutrient solution. Increased $\mathrm{Ca}^{2+}$ concentrations in the nutrient solution al so increased leaf and root $\mathrm{Ca}^{2+}$ contents of both genotypes, but salt stressed sedlings were not able to maintain the same tissueconcentrations of theseions of unstressed control seedlings. Calcium had nosignificant effect on proline accumulation in the plants, either in the absence or presence of salt stress.
\end{abstract}

Index terms: salinity, Sorghum bicolor, seedling growth, $\mathrm{Cl}-, \mathrm{Na}+, \mathrm{K}+$ contents.

\section{INTRODUÇÃO}

A salinidade dos solos é um dos problemas mais limitantes da produção agrícola em regiões áridas e semi-áridas do mundo (Gheyi, 2000; Munns, 2002). Na maioria dessas regiões, a salinização destes sol os ocorre com o acúmulo de determinadas espécies iônicas, principalmente $\mathrm{Na}^{+} \mathrm{e} \mathrm{Cl}^{-}$. A predominância destas espécies iônicas no meio de crescimento, além de causar toxidez, quando se acumulam nos tecidos vegetais, pode acarretar mudanças na capacidade da planta em absorver, transportar eutilizar os íons essenciais ao seu crescimento.

Estudos em sol os com problema de sal inidade têm mostrado que o aumento na concentração de $\mathrm{Na}^{+}$é acompanhado pelo decréscimo na concentração de Ca ${ }^{2+}$ trocável, resultando em um desequilíbrio iônico que pode afetar o crescimento das plantas. Cereais, como, por exemplo, sorgo, milho, arroz e cevada, são particularmente sensíveis à el evação na rel ação $\mathrm{Na}^{+} /$ $\mathrm{Ca}^{2+}$ em sol os afetados por sais, exibindo redução no crescimento e deficiências de $\mathrm{Ca}^{2+}$ (Grieve \& Maas, 1988).

A el evação da concentração de $\mathrm{Ca}^{2+}$ no ambiente radicular tem sido apontada como uma alternativa para minorar os efeitos negativos da salinidade sobre o crescimento das plantas (Rengel, 1992; Lacerda, 1995). Este íon, além de reduzir a absorção de íons potencialmente tóxicos, como o $\mathrm{Na}^{+}$, favorece a absorção de íons essenciais, como o $\mathrm{K}^{+}$(Colmer et al., 1996) e o próprio Ca2+ (Maas \& Grieve, 1987). Recentemente admitiu-se que o $\mathrm{Ca}^{2+}$ também promove o acúmulo de solutos orgânicos, como a prolina (Läuchli et al., 1994; Colmer et al., 1996) ea glicinabetaina (Girija et al., 2002), os quais possibilitariam o estabel ecimento de um equilíbrio osmótico no citoplasma mais compatível com o metabol ismo cel ular, favorecendo o crescimento das plântulas sob condições de estresse salino.

Este trabalho teve como objetivo avaliar a influência do $\mathrm{Ca}^{2+}$ sobre o crescimento e sobre os teores de $\mathrm{Cl}^{-}, \mathrm{Na}^{+}, \mathrm{K}^{+}, \mathrm{Ca}^{2+}$ e de prol ina em plântulas de dois genótipos de sorgo submetidos ao estresse salino.

\section{MATERIAL E MÉTODOS}

Dois genótipos de sorgo forrageiro (Sorghum bicol or (L) M oench), um tolerante (CSF 20) e outro sensível (CSF 18) à salinidade (Lacerda et al., 2001), obtidos do banco de germoplasma da Empresa Pernambucana de Pesquisa Agropecuária, foram utilizados nos experimentos. As sementes, selecionadas quanto ao tamanho e forma, foram esterilizadas superficialmente com solução de 
hipocl orito de sódio $2 \%$ durante 10 minutos. Depois de lavadas em água corrente e desmineralizada, foram colocadas para germinar em rolos de papel 'germtest', mergulhados parcialmenteem solução de Clark (Clark, 1975), pH 5,5, com um quinto de sua força iônica original (Lacerda et al., 2001). A pós sete dias, as plântulas foram transferidas para vasos de polietileno que continham 2,5 L das soluções de tratamento e mantidas em uma sala de crescimento com temperatura de $25 \pm 3{ }^{\circ} \mathrm{C}$, fluxo de fótons de $230 \mu \mathrm{mol} \mathrm{m} \mathrm{m}^{-2} \mathrm{~s}^{-1}$ e fotoperíodo de $16 \mathrm{~h}$, sob arejamento contínuo.

As sol uções detratamento consistiram desoluções deClark modificadas para conter duas concentrações de $\mathrm{Na}^{+}\left(0\right.$ e $\left.75 \mathrm{mmol} \mathrm{L}^{-1}\right)$ e duas de $\mathrm{Ca}^{2+}(0,65 \mathrm{e}$ 2,6 mmol L-1). As concentrações dos íons $\mathrm{Na}^{+}, \mathrm{Ca}^{2+} \mathrm{e}$ $\mathrm{Cl}^{-}$, os potenciais osmóticos e as condutividades elétricas resultantes encontram-se no quadro 1 . O tratamento salino foi obtido pela adição de $\mathrm{Na}^{+} \mathrm{em}$ incrementos de $25 \mathrm{mmol} \mathrm{L}^{-1}$ a cada $12 \mathrm{~h}$, na forma de $\mathrm{NaCl}$, até atingir a concentração final de $75 \mathrm{mmol} \mathrm{L}^{-1}$. As soluções nutritivas foram trocadas após quatro dias, sendo o seu nível mantido pela adi ção diária deágua desmineralizada eopH ajustado diariamente para 5,5. Completados setedias do início da adição de $\mathrm{NaCl}$, as plântulas foram colhidas, separando-se a parte aérea e as raízes, e colocadas em estufa a $80{ }^{\circ} \mathrm{C}$ para obtenção de peso constante.

Os solutos foram determinados em extratos aquosos, obtidos pela incubação de $300 \mathrm{mg}$ de matéria fresca de folhas e de raízes em $15 \mathrm{~mL}$ de água desmineralizada com $0,03 \mathrm{~mL}$ de tolueno em banho-maria a $30^{\circ} \mathrm{C}$, durante $1 \mathrm{~h}$. A extração foi repetida mais duas vezes e o volume completado para $50 \mathrm{~mL}$ com água desmineralizada (Weimberg et al., 1984). Nesse extrato, foram determinados os teores de $\mathrm{Na}^{+}, \mathrm{K}^{+}, \mathrm{Ca}^{2+}$ (Allan, 1969), de $\mathrm{Cl}^{-}$(Gaines et al., 1984) e de prolina (Bates et al., 1973).

O experimento seguiu um delineamento inteiramente casualizado, em esquema fatorial
$(2 \times 2 \times 2)$, com três repetições. Os resultados foram submetidos à análise de variância, e as médias comparadas pelo teste de Tukey com $\mathrm{P} \leq 0,05$.

\section{RESULTADOS E DISCUSSÃO}

O estresse salino, de modo geral, reduziu o crescimento das plântulas dos dois genótipos de sorgo, tendo sido a inibição do crescimento da parte aérea maior do que a das raízes (Quadro 2). As reduções na produção de matéria seca da parte aérea e das raízes causadas pelo estresse sal ino foram de 33 e $41 \%$ e de 8 e $14 \%$ nos genótipos tolerante e sensível, respectivamente. Esses resultados confirmam as diferenças no grau de tolerância à salinidade entre os dois genótipos estudados, as quais são crescentes com o tempo de exposição ao estresse, eevidenciam a maior sensi bilidade da parte aérea à salinidade, conforme demonstrado por Lacerda et al. (2001 e 2003).

O aumento na concentração de $\mathrm{Ca}^{2+}$ na solução nutritiva favoreceu o crescimento somente da parte aérea das plântulas do genótipo tolerante, independentemente do estresse salino aplicado (Quadro 2). O efeito benéfico do $\mathrm{Ca}^{2+}$ no crescimento das plântulas submetidas ao estresse salino, entretanto, foi maior do que no das plântulascontrole. Efeitos similares têm sido observados em outras espécies vegetais e parecem estar relacionados com a redução nas concentrações de íons tóxicos, principalmente de $\mathrm{Na}^{+}$nas fol has (Rengel, 1992). O aumento na concentração de $\mathrm{Ca}^{2+}$, entretanto, não teve efeito significativo sobre a produção de matéria seca das raízes no genótipo tol erante, mas resultou em redução de cerca de $11 \%$ no genótipo sensível (Quadro 2). Os efeitos do $\mathrm{Ca}^{2+}$ sobre o crescimento radicular de plantas submetidas a estresse salino têm-se mostrado bastante variáveis, podendo ir desde pequenas reduções, como as

Quadro 1. Potencial osmótico $\left(\Psi_{s}\right)$, condutividade elétrica (CE) e concentração de alguns íons presentes nas soluções dos tratamentos ${ }^{(1,2)}$

\begin{tabular}{|c|c|c|c|c|c|}
\hline \multirow{2}{*}{ Tratamento } & \multirow{2}{*}{$\Psi_{\mathrm{s}}$} & \multirow{2}{*}{ CE } & \multicolumn{3}{|c|}{ Concentração (mmol L-1) } \\
\hline & & & $\mathrm{Na}^{+}$ & $\mathrm{Ca}^{2+}$ & $\mathrm{Cl}^{-}$ \\
\hline & $-\mathrm{MPa}$ & $\mathrm{dS} / \mathrm{m}$ & $\longrightarrow$ & $65 \mathrm{~mm}$ & - \\
\hline $\begin{array}{l}\text { Controle } \\
\text { Salino }\end{array}$ & $\begin{array}{l}0,056 \\
0,375\end{array}$ & $\begin{array}{l}1,300 \\
7,273\end{array}$ & $\begin{array}{r}3,90 \\
75,00\end{array}$ & $\begin{array}{l}0,65 \\
0,65\end{array}$ & $\begin{array}{r}0,00 \\
71,10\end{array}$ \\
\hline $\begin{array}{l}\text { Controle } \\
\text { Salino }\end{array}$ & $\begin{array}{l}0,062 \\
0,385\end{array}$ & $\begin{array}{l}1,513 \\
7,470\end{array}$ & $\begin{array}{r}3,90 \\
75,00\end{array}$ & $\begin{array}{l}2,60 \\
2,60\end{array}$ & $\begin{array}{r}3,90 \\
75,00\end{array}$ \\
\hline
\end{tabular}

(1) As concentrações dos íons foram estimadas com base nos sais utilizados, enquanto os val ores do potencial osmótico e da condutividade elétrica foram medidos experimentalmente. ${ }^{(2)}$ Os demais íons componentes da solução de Clark não foram modificados e suas

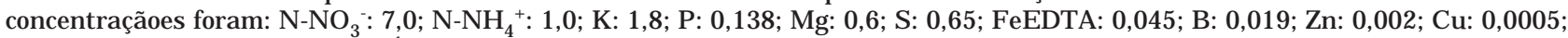
$\mathrm{Mn}: 0,007$ e $\mathrm{Mo:} 0,0006 \mathrm{mmol}^{-1}$. 


\section{Quadro 2. Produção de matéria seca de plântulas de dois genóti pos de sorgo, sob duas concentrações de $\mathrm{Ca}^{2+}$, submetidos ou não a estresse salino}

\begin{tabular}{|c|c|c|c|c|c|}
\hline \multirow{3}{*}{ G enótipo } & \multirow{3}{*}{ Tratamento } & \multicolumn{4}{|c|}{ Matéria seca(1) } \\
\hline & & \multicolumn{2}{|c|}{ Parte aérea } & \multicolumn{2}{|c|}{ Raiz } \\
\hline & & $\mathrm{Ca}^{2+} 0,65 \mathrm{~m} \mathrm{~mol} \mathrm{~L}^{-1}$ & $\mathrm{Ca}^{2+} 2,60 \mathrm{mmol} \mathrm{L}^{-1}$ & $\mathrm{Ca}^{2+} 0,65 \mathrm{mmol}^{-1}$ & $\mathrm{Ca}^{2+} 2,60 \mathrm{~m} \mathrm{~mol} \mathrm{~L}^{-1}$ \\
\hline Tolerante & $\begin{array}{l}\text { Controle } \\
\text { Salino }\end{array}$ & $\begin{array}{l}\text { b0,462 aA } \\
\text { b0,300 bA }\end{array}$ & $\begin{array}{l}\mathrm{a} 0,516 \text { aA } \\
\mathrm{a} 0,351 \mathrm{bA}\end{array}$ & $\begin{array}{l}\mathrm{a} 0,185 \text { aB } \\
\mathrm{a} 0,172 \mathrm{aA}\end{array}$ & $\begin{array}{l}\mathrm{a} 0,185 \text { aA } \\
\mathrm{a} 0,167 \mathrm{bA}\end{array}$ \\
\hline Sensível & $\begin{array}{l}\text { Controle } \\
\text { Salino }\end{array}$ & $\begin{array}{l}\mathrm{a} 0,364 \mathrm{aB} \\
\mathrm{a} 0,215 \mathrm{bB}\end{array}$ & $\begin{array}{l}\mathrm{a} 0,384 \mathrm{aB} \\
\mathrm{a} 0,227 \mathrm{bB}\end{array}$ & $\begin{array}{l}\mathrm{a} 0,209 \text { aA } \\
\mathrm{a} 0,179 \mathrm{bA}\end{array}$ & $\begin{array}{l}\mathrm{b} 0,188 \text { aA } \\
\mathrm{b} 0,160 \mathrm{bA}\end{array}$ \\
\hline
\end{tabular}

(1) Médias seguidas pelas mesmas letras maiúsculas entre genótipos para cada tratamento e nível de Ca, pelas mesmas letras minúsculas entre tratamentos para cada genótipo e nível de Ca e pelas mesmas letras minúsculas subscritas à esquerda entre níveis de $\mathrm{Ca}$, para tratamento e genótipo, não diferem estatisticamente entre si pelo teste de Tukey, com $\mathrm{P} \leq 0,05$.

observadas no presente estudo, até aumentos bastante significativos, dependendo da espécie, das condições experimentais e de outros fatores (Cramer et al., 1986).

O estresse salino resultou em aumento bastante el evado nos teores de $\mathrm{Na}^{+}$e de $\mathrm{Cl}^{-}$nas fol has, principalmente no genótipo sensível (Quadro 3), o que explica, pelo menos em parte, a maior sensibilidade desse genótipo ao estresse salino (Lacerda et al., 2003). Com o aumento na concentração de $\mathrm{Ca}^{2+}$ na solução nutritiva, observou-se redução nos teores de $\mathrm{Na}^{+}$de cerca de 47 e $30 \%$ nas fol has dos genótipos tolerante e sensível, respectivamente, porém apenas em plântulas sob estresse salino. Esta redução se deve, provavelmente, ao melhor controle na absorção radicular e no transporte de $\mathrm{Na}^{+}$para a parte aérea que ocorre em níveis adequados de $\mathrm{Ca}^{2+}$ no meio de nutrição (Läuchli, 1990) etem sido apontada como um dos principais efeitos benéficos do $\mathrm{Ca}^{2+}$ em plantas sob condiç̧ões de estresse sal ino (Rengel, 1992). Tal redução nos teores de $\mathrm{Na}^{+}$nas fol has, contudo, nem sempre parece estar relacionada com mel horia no crescimento vegetativo de plantas sob estresse salino (Lacerda, 1995). De acordo com Reid $\&$ Smith (2000), oaumento na concentração de $\mathrm{Ca}^{2+}$ no meio de nutrição não afeta igual mente o crescimento vegetativo e a absorção de $\mathrm{Na}^{+}$. Segundo eles, a concentração de $\mathrm{Ca}^{2+}$ requerida para afetar o crescimento é menor do que a necessária ao controle da absorção de $\mathrm{Na}^{+}$, em plantas sob estresse salino. A parentemente, os efeitos benéficos do $\mathrm{Ca}^{2+}$ na redução da toxidez do $\mathrm{Na}^{+}$podem ser sobrepujados pelos efeitos osmóticos associados com o aumento da concentração total de sais.

Reduções nos teores de $\mathrm{Cl}^{-}$, com o aumento na concentração de $\mathrm{Ca}^{2+}$, ocorreram nas fol has dos dois genóti pos, porém foram usual mente menores do que as de $\mathrm{Na}^{+}$(Quadro 3). Vale salientar que as concentrações de $\mathrm{Cl}^{-}$na solução nutritiva, em razão dos ajustes nas concentrações de $\mathrm{Na}^{+}$e $\mathrm{Ca}^{2+}$, não foram exatamente as mesmas em todos os tratamentos (Quadro 1).
Os teores de $\mathrm{Na}^{+}$e de $\mathrm{Cl}^{-}$aumentaram nas raízes com o estresse salino, tendo sido os aumentos maiores no genótipo sensível (Quadro 3). Sob estresse salino, os teores de $\mathrm{Cl}^{-}$não se modificaram, enquanto os de $\mathrm{Na}^{+}$reduziram com o aumento na concentração de $\mathrm{Ca}^{2+}$ na solução nutritiva em cerca de 32 e $26 \%$ nos genóti pos anal isados, tol erante esensível, respectivamente. I stose deve, provavelmente, aofato de ser o $\mathrm{Ca}^{2+}$ essencial para a sel etividade de canais de cátions na plasmalema de células das raízes, tendo, conseqüentemente, efeito sobre o influxo passivo de $\mathrm{Na}^{+}$(Davenport et al., 1997).

Sob estresse salino, observou-se redução nos teores de $\mathrm{K}^{+}$nas fol has dos dois genótipos, independentemente da concentração de $\mathrm{Ca}^{2+}$ (Quadro 3). O genótipo tolerante manteve sempre maiores teores de $\mathrm{K}^{+}$nas fol has, o que pode ter contribuído para a maior tolerância desse genótipo ao estresse salino, conforme sugerem Taleisnik \& Grunberg, (1994), Bernstein et al. (1995) e Lacerda et al. (2001). Em geral, o aumento na concentração de $\mathrm{Ca}^{2+}$ na solução nutritiva resultou em aumento nos teores de $\mathrm{K}^{+}$nas fol has do genótipo tolerante, mas praticamente não influiu nos teores deste íon nas folhas do genótipo sensível. Por ser o $\mathrm{K}^{+}$ extremamente importante ao metabolismo das plantas, a manutenção de teores foliares mais elevados deste íon foi fundamental para a maior produção de matéria seca observada no genótipo tolerante (Quadro 2).

Nas raízes, sob estresse salino, observou-se redução nos teores de $\mathrm{K}^{+}$nas plântulas dos dois genótipos, independentemente da concentração de $\mathrm{Ca}^{2+}$ (Quadro 3). Em todos os tratamentos, entretanto, o genótipo sensível foi capaz de manter teores mais el evados deste íon, embora isto não tenha resultado em maior produção de matéria seca de raízes neste genótipo (Quadro 2). O aumento na concentração de $\mathrm{Ca}^{2+}$ resultou em aumentos nos teores de K+ nas raízes dos dois genótipos, exceto nas plântulas-controle do genótipo sensível. 
Quadro 3. Teores de íons e prolina em folhas e raízes de plântulas de dois genótipos de sorgo, sob duas concentrações de $\mathrm{Ca}^{2+}$, submetidos ou não a estresse salino

\begin{tabular}{|c|c|c|c|c|c|}
\hline \multirow{2}{*}{ Genótipo } & \multirow{2}{*}{ Tratamento } & \multicolumn{2}{|c|}{ Folha } & \multicolumn{2}{|c|}{ Raiz } \\
\hline & & $\mathrm{Ca}^{2+}$ 0,65 mmol L-1 & $\mathrm{Ca}^{2+} 2,60 \mathrm{mmol} \mathrm{L}^{-1}$ & $\mathrm{Ca}^{2+} 0,65 \mathrm{mmol} \mathrm{L}^{-1}$ & $\mathrm{Ca}^{2+} 2,60 \mathrm{mmol} \mathrm{L}^{-1}$ \\
\hline & & & $\mathrm{mmol}$ & $1 \mathrm{MS}^{(1)}$ & - \\
\hline & & & & & \\
\hline \multirow[t]{10}{*}{ Tolerante } & $\begin{array}{l}\text { Controle } \\
\text { Salino }\end{array}$ & $\begin{array}{l}\mathrm{a} 205,3 \mathrm{bA} \\
\mathrm{a} 436,1 \mathrm{aB}\end{array}$ & $\begin{array}{l}\text { a 239, } 1 \text { bA } \\
\text { b356, } 1 \text { aB }\end{array}$ & $\begin{array}{l}\text { a } 163,8 \mathrm{bA} \\
\mathrm{a} 428,3 \mathrm{aB}\end{array}$ & $\begin{array}{l}\text { a } 204,0 \mathrm{bA} \\
\mathrm{a} 429,6 \mathrm{aB}\end{array}$ \\
\hline & & & & & \\
\hline & $\begin{array}{l}\text { Controle } \\
\text { Salino }\end{array}$ & $\begin{array}{r}a 48,5 \mathrm{bA} \\
a 438,6 \mathrm{aB}\end{array}$ & $\begin{array}{r}a 24,0 \mathrm{bA} \\
\mathrm{b} 233,8 \mathrm{aB}\end{array}$ & $\begin{array}{l}\mathrm{a} 104,1 \mathrm{bA} \\
\mathrm{a} 868,1 \mathrm{aB}\end{array}$ & $\begin{array}{r}\text { a } 75,6 \mathrm{bA} \\
\text { b593,1 aB }\end{array}$ \\
\hline & & & & & \\
\hline & $\begin{array}{l}\text { Controle } \\
\text { Salino }\end{array}$ & $\begin{array}{l}\text { b500,3 aA } \\
\text { b366,1 bA }\end{array}$ & $\begin{array}{l}\text { a 551,5 aA } \\
\text { a } 432,7 \mathrm{bA}\end{array}$ & $\begin{array}{l}\mathrm{b} 778,8 \mathrm{aB} \\
\mathrm{b} 572,5 \mathrm{bB}\end{array}$ & $\begin{array}{l}\text { a } 913,8 \mathrm{aB} \\
\mathrm{a} 662,2 \mathrm{bB}\end{array}$ \\
\hline & & & & & \\
\hline & $\begin{array}{l}\text { Controle } \\
\text { Salino }\end{array}$ & $\begin{array}{l}\mathrm{b} 33,9 \mathrm{aB} \\
\mathrm{b} 31,8 \mathrm{aA}\end{array}$ & $\begin{array}{l}a 63,8 \text { aB } \\
a 44,4 \mathrm{bB}\end{array}$ & $\begin{array}{l}\text { a } 24,3 \text { aA } \\
\text { a24,6 aA }\end{array}$ & $\begin{array}{l}a 37,6 \mathrm{aB} \\
\mathrm{a} 29,3 \mathrm{aB}\end{array}$ \\
\hline & & & & & \\
\hline & $\begin{array}{l}\text { Controle } \\
\text { Salino }\end{array}$ & $\begin{array}{r}a 4,4 \mathrm{bA} \\
\mathrm{a} 12,8 \mathrm{aB}\end{array}$ & $\begin{array}{r}\mathrm{a} 5,0 \mathrm{bA} \\
\mathrm{a} 13,5 \mathrm{aB}\end{array}$ & $\begin{array}{l}\mathrm{b} 4,1 \mathrm{aB} \\
\mathrm{a} 4,8 \mathrm{aA}\end{array}$ & $\begin{array}{l}\mathrm{a} 5,6 \mathrm{aA} \\
\mathrm{a}, 7 \mathrm{aA}\end{array}$ \\
\hline & & & & & \\
\hline \multirow[t]{9}{*}{ Sensível } & $\begin{array}{l}\text { Controle } \\
\text { Salino }\end{array}$ & $\begin{array}{l}\text { a192,9 bA } \\
\text { a551,9 aA }\end{array}$ & $\begin{array}{l}\mathrm{a} 230,6 \mathrm{bA} \\
\mathrm{b} 428,4 \mathrm{aA}\end{array}$ & $\begin{array}{l}a 186,3 \mathrm{bA} \\
\mathrm{a} 626,3 \mathrm{aA}\end{array}$ & $\begin{array}{l}a 223,4 \mathrm{bA} \\
\mathrm{a} 645,8 \mathrm{aA}\end{array}$ \\
\hline & & & & & \\
\hline & $\begin{array}{l}\text { Controle } \\
\text { Salino }\end{array}$ & $\begin{array}{r}a 67,4 \mathrm{bA} \\
a 675,5 \mathrm{aA}\end{array}$ & $\begin{array}{r}\text { a52,2 bA } \\
\text { ь470,5 aA }\end{array}$ & $\begin{array}{r}\text { a132,3 bA } \\
\text { a1014,3 aA }\end{array}$ & $\begin{array}{l}\text { a } 122,7 \mathrm{bA} \\
\mathrm{b} 750,0 \mathrm{aA}\end{array}$ \\
\hline & & & & & \\
\hline & $\begin{array}{l}\text { Controle } \\
\text { Salino }\end{array}$ & $\begin{array}{l}\text { a } 495,8 \text { aA } \\
\text { a } 337,7 \mathrm{bA}\end{array}$ & $\begin{array}{l}\text { a } 464,5 \mathrm{aB} \\
\text { a } 342,4 \mathrm{bB}\end{array}$ & $\begin{array}{r}\text { a 1009,8 aA } \\
\text { b658,3 bA }\end{array}$ & $\begin{array}{r}\text { a } 1012,6 \mathrm{aA} \\
\mathrm{a} 774,9 \mathrm{bA}\end{array}$ \\
\hline & & & & & \\
\hline & $\begin{array}{l}\text { Controle } \\
\text { Salino }\end{array}$ & $\begin{array}{l}\text { b53,9 aA } \\
\text { b38,3 bA }\end{array}$ & $\begin{array}{r}\text { a } 100,0 \text { aA } \\
\text { a } 70,8 \text { bA }\end{array}$ & $\begin{array}{l}\text { b31,5 aA } \\
\text { b36,4 aA }\end{array}$ & $\begin{array}{l}\text { a58,2 aA } \\
\text { a } 51,2 \text { aA }\end{array}$ \\
\hline & & & & & \\
\hline & $\begin{array}{l}\text { Controle } \\
\text { Salino }\end{array}$ & $\begin{array}{r}\text { a5,7 bA } \\
\text { a } 33,3 \text { aA }\end{array}$ & $\begin{array}{r}\text { a7,2 bA } \\
\text { a } 36,7 \text { aA }\end{array}$ & $\begin{array}{l}\text { a5,5 aA } \\
\text { a5,3 aA }\end{array}$ & $\begin{array}{l}\text { a5,9 aA } \\
{ }_{a}^{5}, 2 \text { aA }\end{array}$ \\
\hline
\end{tabular}

(1) Médias seguidas pelas mesmas letras maiúsculas entre genótipos para cada tratamento e concentração de Ca, pelas mesmas letras minúsculas entre tratamentos para cada genótipo e concentração de Ca e pelas mesmas letras minúsculas subscritas à esquerda entre concentrações de $\mathrm{Ca}$, para cada tratamento e genótipo, não diferem estatisticamente entre si pelo teste de Tukey, com $\mathrm{P} \leq 0,05$.

O estresse salinonão influenciou os teores deCa2+ nas raízes, porém reduziu os seus teores nas fol has, principal mente no genótipo sensível (Quadro 3). No tratamento com a concentração mais el evada de $\mathrm{Ca}^{2+}$, observou-se aumento nos teores tissulares deste íon nos dois genótipos, principalmente nas plântulas-controle. Sob estressesalino, entretanto, as plântulas não foram capazes de manter as mesmas concentrações foliares de $\mathrm{Ca}^{2+}$, apresentando, em média, teores $30 \%$ mais baixos do que nas plântulas-controle. Segundo tais resultados, as concentrações de $\mathrm{Ca}^{2+}$ utilizadas no presente experimento, mesmo na mais elevada, que corresponde à concentração deste íon na solução de Clark, não foram suficientementeal tas para atingir a chamada "concentraçãolimite" defendida por Reid \& Smith (2000), que permitiria às plantas manterem sob estresse salino teores tissulares adequados de $\mathrm{Ca}^{2+}$.

Acúmulo de prol ina resultante do estresse sal ino somente foi observado nas folhas, principalmente no genótipo sensível, e mostrou-se independente da concentração de $\mathrm{Ca}^{2+}$ do meio nutritivo (Quadro 3). Embora os aumentos percentuais de prolina com o estresse salinotenham sido el evados, os teores deste soluto orgânico, entretanto, permaneceram sempre muito baixos, comparativamente aos dos íons e 
foram mais el evados no genóti po sensível, mostrando a inexistência de uma participação efetiva deste soluto nos mecanismos de tolerância à salinidade em sorgo, pelo menos, nas condições deste experimento.

Aparentemente, a salinidade, ao influenciar diferencialmente as absorções de $\mathrm{Na}^{+}$e de $\mathrm{K}^{+}$e, provavelmente, a translocação deles para a parte aérea, controla o estabel ecimento de diferentes relações $\mathrm{Na}^{+} / \mathrm{K}^{+}$entre os órgãos das planta e entre os genótipos (Quadro 4). Nas folhas, o genótipo tolerante apresentou uma relação $\mathrm{Na}^{+} / \mathrm{K}^{+}$bem inferior à observada no genóti po sensível, diferença esta que foi ainda mais marcante na concentração mais el evada de $\mathrm{Ca}^{2+}$ na soluçãonutritiva. Esteefeito do $\mathrm{Ca}^{2+}$ correlacionou-se com maior produtividade das plântulas do genótipo tolerante sob as mesmas condições experimentais (Quadro 2). Resultados como este evidenciam que um dos principais papéis do $\mathrm{Ca}^{2+}$ em plantas cultivadas em ambientes sal inos pode ser o controle da absorção radicular de $\mathrm{Na}^{+} \mathrm{e}$ de $\mathrm{K}^{+}$, atuando na membrana celular efavorecendo a manutenção de teores mais adequados desses íons nos tecidos fotossintetizantes. $\mathrm{O} \mathrm{Ca}{ }^{2+}$, portanto, tem influência decisiva na manutenção da seletividade $\mathrm{K}^{+} / \mathrm{Na}^{+}$, como sugerida por outros autores (Colmer et al., 1996), devendo ser suas concentrações nos meios de cultivos claramente definidas quando a relação $\mathrm{K}^{+} / \mathrm{Na}^{+}$for utilizada como indicador da tolerância de plantas à salinidade.

\section{CONCLUSÕES}

1. O $\mathrm{Ca}^{2+}$ foi fundamental para a manutenção de teores mais adequados de íons nos tecidos vegetais, principalmente nas folhas do genótipo tolerante, tendo o aumento na sua concentração no meio de cultivo reduzido parcialmente os efeitos da salinidade sobrea produção de matéria seca apenas da parte aérea do genóti po tolerante de sorgo.
2. $\mathrm{Na}$ presença de $\mathrm{Ca}^{2+}$, as folhas do genótipo tol erante apresentaram sob estresse salino uma relação $\mathrm{Na}^{+} / \mathrm{K}^{+}$mais baixa do que do sensível emaior produção de matéria seca.

3. As plantas sob estresse salino não foram capazes de manter teores tissulares adequados de $\mathrm{Ca}^{2+}$ mesmo quando cultivadas na concentração mais el evada deste íon no meio de cultivo.

4. Não se detectou correlação entre as concentrações de $\mathrm{Ca}^{2+}$ na solução nutritiva e o acúmulo de prolina em fol has e raízes de plantas sob estresse salino.

\section{AGRADECIMENTOS}

Os autores agradecem À FAPEMIG, CAPES e CNPq, pel osuportefinanceiro dado para a realização deste trabalho, e ao Dr. J osé Nildo Tabosa (IPA$P E)$, pelas sementes dos materiais genéticos utilizados neste estudo.

\section{LITE RATURA CITADA}

ALLAN, J.E. The preparation of agricultural samples for analysis by atomic absorption spectroscopy. Varian Techtron, 1969. 15p. (Bulletim 12/69)

BERNSTEIN, N.; SILK, W.K. \& LÄUCHLI, A. Growth and development of sorghum leaves under conditions of $\mathrm{NaCl}$ stress: possible role of some mineral elements in growth inhibition. Planta, 196:699-705, 1995.

BATES, L.S.; WALDREN, R.P. \& TEARE, I.D. Rapid determination of free prolinefor water-stress studies. Plant Soil, 39:205-207, 1973.

CLARK, R.B. Characterization of phosphatase of intact maize roots. J . Agric. Food Chem., 23:458-460, 1975.

COLMER, T.D.; FAN, T.W.M.; HIGASHI, R.M. \& LÄUCHLI, A. Interactive effects of $\mathrm{Ca}^{2+}$ and $\mathrm{NaCl}$ stress on the ionic relations and proline accumulation in the primary root tip of Sorghum bicolor. Physiol. Plant., 97:421-424, 1996.

Quadro 4. Relação $\mathrm{Na}^{+} / \mathrm{K}^{+}$em folhas e raízes de plântulas de dois genótipos de sorgo, sob duas concentrações de $\mathrm{Ca}^{2+}$, submetidos ou não a estresse salino ${ }^{(1)}$

\begin{tabular}{|c|c|c|c|c|c|}
\hline \multirow{3}{*}{ Genótipo } & \multirow{3}{*}{ Tratamento } & \multicolumn{4}{|c|}{ Relação $\mathrm{Na}^{+} / \mathbf{K}^{+}$} \\
\hline & & \multicolumn{2}{|c|}{ Folha } & \multicolumn{2}{|c|}{ Raiz } \\
\hline & & $\mathrm{Ca}^{2+}$ 0,65 mmol L-1 & $\mathrm{Ca}^{2+} 2,60 \mathrm{mmol} \mathrm{L}^{-1}$ & $\mathrm{Ca}^{2+}$ 0,65 mmol L-1 & $\mathrm{Ca}^{2+} 2,60 \mathrm{mmol} \mathrm{L}^{-1}$ \\
\hline Tolerante & $\begin{array}{l}\text { Controle } \\
\text { Salino }\end{array}$ & $\begin{array}{l}\mathrm{a} 0,05 \mathrm{bA} \\
\mathrm{a} 1,09 \mathrm{aB}\end{array}$ & $\begin{array}{l}\mathrm{a} 0,04 \mathrm{bA} \\
\mathrm{b} 0,40 \mathrm{aB}\end{array}$ & $\begin{array}{l}\mathrm{a} 0,13 \text { bA } \\
\mathrm{a} 1,52 \mathrm{aA}\end{array}$ & $\begin{array}{l}\text { a0,08 bA } \\
\text { b0,90 aA }\end{array}$ \\
\hline Sensível & $\begin{array}{l}\text { Controle } \\
\text { Salino }\end{array}$ & $\begin{array}{l}\mathrm{a} 0,10 \mathrm{bA} \\
\mathrm{a} 1,99 \mathrm{aA}\end{array}$ & $\begin{array}{l}\mathrm{a} 0,07 \mathrm{bA} \\
\mathrm{b} 1,37 \mathrm{aA}\end{array}$ & $\begin{array}{l}\mathrm{a} 0,13 \mathrm{bA} \\
\mathrm{a} 1,54 \mathrm{aA}\end{array}$ & $\begin{array}{l}\mathrm{a} 0,12 \text { bA } \\
\mathrm{b} 0,97 \mathrm{aA}\end{array}$ \\
\hline
\end{tabular}

(1) Médias seguidas pelas mesmas letras maiúsculas entre genótipos para cada tratamento e concentração de Ca, pelas mesmas letras minúsculas entre tratamentos para cada genótipo e concentração de Ca e pelas mesmas letras minúsculas subscritas à esquerda entre concentrações de Ca, para cada tratamento e genótipo, não diferem estatisticamente entre si pelo teste de Tukey, com $\mathrm{P} \leq 0,05$. 
CRAMER, G.; LÄUCHLI, A. \& EPSTEIN, E. Effects of $\mathrm{NaCl}$ and $\mathrm{CaCl}_{2}$ on ion activity in complex nutrient solution and root growth of cotton. Plant Physiol., 81:792-797, 1986.

DAVENPORT, R.J .; REID, R.J . \& SMITH, F. A sodium-calcium interactions in two wheat species differing in salinity tolerance. Physiol. Plant., 99:323-327, 1997.

GAINES, T.P.; PARKER, M.B. \& GASCHO, G.J . Automated determination of chlorides in soil and plant tissue by sodium nitrate. Agron. J ., 76:371-374, 1984.

GHEYI, H.R.. Problemas de salinidade na agricultura irrigada. In: OLIVEIRA, T, ASSIS J R., R.N. ROMERO, R.E. \& SILVA, J .R.C., eds. Agricultura, sustentabilidade e o semiárido. Viçosa, Sociedade Brasileira de Ciência doSolo, 2000, p.329-345.

GIRIJ A, C.; SMITH, B.N. \& SWAMY, P.M. Interactive effects of sodium chlorideand calcium chloride on the accumulation of proline and glycinebetaine in peanut (Arachis hypogaea L.). Environ. Exp. Bot., 47:1-10, 2002.

GRIEVE, C.M. \& MAAS, E.V. Differential effects of sodium/ calcium ratio on sorghum genotypes. Crop Sci., 28:659-665, 1988.

LACERDA, C.F. Efeitos da salinidade no desenvolvimento e composição mineral do feijão-de-corda (Vigna unguiculata (L.) Walp.) e utilização do $\mathrm{Ca}^{2+}$ como meio para minorar tais efeitos. Fortaleza, Universidade Federal do Ceará, 1995, 87p. (Tese de Mestrado)

LACERDA, C.F.; CAMBRAIA, J .; CANO, M.A.O. \& RUIZ, H.A. Plant growth and solute accumulation and distribution in two sorghum genotypes, under $\mathrm{NaCl}$ stress. R. Bras. Fisiol. Veg., 13:270-284, 2001.
LACERDA, C.F.; CAMBRAIA, J .; CANO, M.A.O.; RUIZ, H.A \& PRISCO, J .T. Solute accumulation and distribution during shoot and leaf development in two sorghum genotypes under salt stress. Env. Exp. Bot., 49:107- 120, 2003.

LÄUCHLI, A. Calcium, salinity and the plasma membrane. In: LEONARD, R.T. \& HEPLER, P.K., eds. Calcium in plant growth. Rockville, The American Society of Plant Physiologist, 1990. p.26-35.

LÄUCHLI, A.; COLMER, T.D.; FAN, T.W. \& HIGASHI, R.M. Solute regulation by calcium in salt-stressed plants. In: CHERRY, J.H., ed. Biochemical and cellular mechanisms of stress tolerance in plants. Berlim, Springer-Verlag, 1994. p.443-461. (NATO ASI Series, H86)

MAAS, E.V.\& GRIEVE, C.M. Sodium-induced calcium deficiency in salt stressed corn. Plant, Cell Environ., 10:559-564, 1987.

MUNNS, R. Comparative physiology of salt and water stress. Plant, Cell Environ., 25:239-250, 2002.

REID, R.J . \& SMITH, A. Thelimits of sodium/calcium interactions in plant growth. Aust. J . Plant Physiol., 27:709-715, 2000.

RENGEL, Z. The role of calcium in salt toxicity. Plant, Cell Environ., 15:625-632, 1992.

TALEISNIK, E. \& GRUNBERG, K. I on balance in tomato cultivars differing in salt tolerance. I. Sodium and potassium accumulation and fluxes under moderate salinity. Physiol. Plant., 92:528-534, 1994.

WEIMBERG, R.; LERNER, H.R. \& POLJ AKOFF-MAYBER, A. Changes in growth and water soluble concentrations in Sorghum bi col or stressed with sodium and potassium salts. Physiol. Plant., 62:472-480, 1984. 
